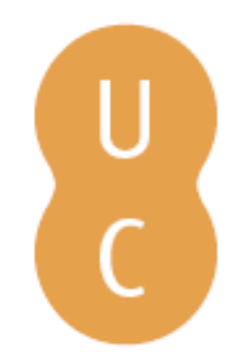

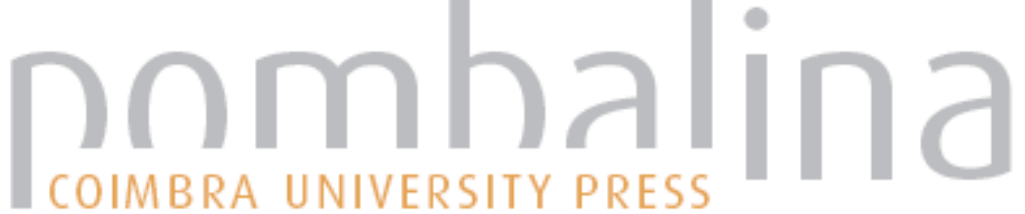

\section{Coimbra ou Berlim? Humboldt ou Pombal?}
Autor(es): $\quad$ Santos, Fernando Seabra
Publicado por: Imprensa da Universidade de Coimbra
URL
persistente:
URI:http://hdl.handle.net/10316.2/38443
DOI:
DOI:http://dx.doi.org/10.14195/978-989-26-0764-1_7

Accessed : $\quad$ 26-Apr-2023 14:06:43

A navegação consulta e descarregamento dos títulos inseridos nas Bibliotecas Digitais UC Digitalis, UC Pombalina e UC Impactum, pressupõem a aceitação plena e sem reservas dos Termos e Condições de Uso destas Bibliotecas Digitais, disponíveis em https://digitalis.uc.pt/pt-pt/termos.

Conforme exposto nos referidos Termos e Condições de Uso, o descarregamento de títulos de acesso restrito requer uma licença válida de autorização devendo o utilizador aceder ao(s) documento(s) a partir de um endereço de IP da instituição detentora da supramencionada licença.

Ao utilizador é apenas permitido o descarregamento para uso pessoal, pelo que o emprego do(s) título(s) descarregado(s) para outro fim, designadamente comercial, carece de autorização do respetivo autor ou editor da obra.

Na medida em que todas as obras da UC Digitalis se encontram protegidas pelo Código do Direito de Autor e Direitos Conexos e demais legislação aplicável, toda a cópia, parcial ou total, deste documento, nos casos em que é legalmente admitida, deverá conter ou fazer-se acompanhar por este aviso.

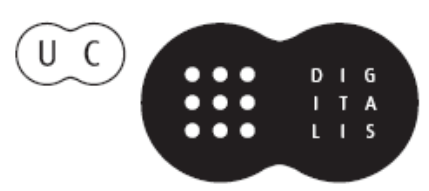


Professor Catedrático da Universidade de Coimbra e Professor Visitante da Universidade de Brasília (Bolseiro do Programa CAPES/PVE)

fseabra@ci.uc.pt

\section{Coimbra ou Berlim? Humboldt ou Pombal?}

\section{Fernando Seabra Santos}

Herdeira de experiências civilizacionais fundadoras muito anteriores, das quais é legítimo recordar a Academia de Atenas, o Liceu de Aristóteles, o Jardim de Epicuro, a Biblioteca de Alexandria, a Escola de Nalanda, as madrasah islâmicas ou a Escola de Toledo, a Universidade foi reinventada na Europa Ocidental há quase mil anos. Constituiu-se no contexto do renascimento comercial e urbano do início do segundo milénio, em consequência do qual se havia assistido ao aumento extraordinário do número de escolas secundárias catedralícias que se espalharam por todo o continente e ao surgimento de corporações - representação de interesses comuns - de estudantes e professores, formalmente reconhecidas através de bulas papais ou de cartas de outorga de imperadores e de reis, que evoluíram para o que hoje se designa de Universidade.

Bolonha (no ano 1088), Paris (em 1090 ou 1170) e Oxford (em 1096), foram os centros urbanos medievais onde se organizaram essas primeiras instituições, que tinham uma estrutura semelhante nos seus estudos básicos, ou propedêuticos, de filosofia, também designados de artes liberais: o trivium, estudos dedicados à linguagem, representados pela gramática, pela lógica e pela retórica, e o quadrivium, constituído pela aritmética, pela geometria, pela astronomia e pela música. A estrutura curricular desses estudos gerais (studium generale) dava continuidade a uma tradição que se iniciou na Academia de Platão e era complementada pelos cursos de Direito, de Teologia e, posteriormente, de Medicina, que constituíam o nível superior de ensino.

Em Bolonha o curso de Direito compreendia o estudo do Corpus Juris Civilis dos romanos e o direito canónico, e em Paris, o curso de Teologia destacava-se por atrair grandes mestres da filosofia escolástica. Quanto ao curso de Medicina, embora antes da constituição formal das universidades já existissem escolas de preparação de médicos - como a pioneira escola de Salerno criada no século X - é somente no século XIII que passa a integrar universidades (Montpellier: 1220, Salerno: 1231). Com a redescoberta do pensamento de Aristóteles para a qual largamente contribuiu a Escola de Toledo, ou de uma forma mais generalizada e provavelmente mais correta, na sequência do percurso norte-africano do pensamento grego, no qual se devem incluir as importantes contribuições originais de numerosos cientistas do mundo islâmico, os estudos até então considerados propedêuticos de filosofia (ou de artes) tomaram uma outra importância e dignidade universitária, passando esta componente do ensino a organizar-se numa Faculdade a par das restantes três, embora com um estatuto inferior. A formação 
para as "artes mecânicas" (embriōes das futuras Escolas de Engenharia), permaneceria de fora das Universidades, sendo objecto de iniciativas isoladas de base estatal, tais como a mítica (mas sem existência documentada) Escola de Sagres para as artes náuticas, ou as escolas militares para as artes bélicas.

As universidades expandiram-se por toda a Europa Medieval de tal forma que no final do século XIII já havia quinze. Em 1500 esse número chegava às cinquenta. Inicialmente destinadas a guardar e a proteger os valores da civilização (cristã, na sua origem europeia), elas viram essa função, reinterpretada pelo tempo, transformar-se em princípio instituinte, no quadro do qual a educação superior se assumiu como a sua primeira missão.

Até aos séculos XVII e XVIII, o ensino organiza-se em duas bases fundamentais: a lectio e a disputatio. $\mathrm{Na}$ lectio, só o mestre tem a palavra. São lidos trechos de uma obra de referência e por ele comentadas as "opinióes" (sententiae) dos autores. A disputatio era uma livre discussão entre o mestre e o discípulo, na qual se aduziam e discutiam argumentos favoráveis e contrários a uma tese. Ainda assim, o ensino era inteiramente dominado pela escolástica com a finalidade de tentar fazer uma aplicação da filosofia aos mistérios da fé, sistematizando-os em conjunto e em unidade, procurando resolver os conflitos com recurso à razão, mas nunca pondo em causa, mesmo na abordagem menos conservadora de Tomás de Aquino, em última análise, o primado da segunda sobre a primeira.

Não é, portanto, de estranhar, que a revolução científica do século XVII, bem como o modelo inteiramente novo que propõe para o estudo da Natureza, não surja nem se desenvolva no interior das universidades, embora dois grandes nomes desse movimento, Galileu e Newton, tenham sido nelas professores. A resistência e até a hostilidade das instituições universitárias dessa época ao "novo saber" explica o aparecimento, por regra à margem das universidades, de numerosas sociedades científicas, sob a forma de academias, jardins botânicos, observatórios, laboratórios e museus onde ele se produzia e ensinava, então sob a denominação de filosofia natural, em ambientes que se constituíam em verdadeiras comunidades epistemológicas e tiveram um papel decisivo no desenvolvimento do conhecimento científico.

O primeiro movimento de reflexão e de sistematização teórica na direcção do que se poderia chamar de reforma universitária só se iria encontrar já perto do final do século XVIII, numa obra da alta maturidade de um dos maiores filósofos da civilização ocidental, Immanuel Kant. Ele publicou em 1798 um pequeno grande livro chamado $O$ Conflito das Faculdades, um dos textos filosóficos de maior impacto sobre os processos históricos de transformação institucional. Kant anteviu a primeira reforma universitária, ao denunciar os últimos resquícios do carácter sacro da universidade, bem como a ingerência do Estado na sua autonomia.

Ainda no século XVIII a universidade tinha, como vimos, três faculdades superiores, Teologia, Direito e Medicina, e uma faculdade inferior, a de Filosofia. Kant analisa criticamente a estrutura do ensino superior do seu tempo: a verdade da Faculdade de Teologia era estabelecida pela divindade; a verdade da Faculdade de Direito submetia-se à vontade do soberano; a verdade da Faculdade de Medicina advinha do princípio de autoridade. Ele argumenta com clareza que a verdade da Faculdade de Filosofia resultava do escrutínio científico do mundo e que, portanto, as faculdades inferiores deveriam ter como princípio não se ater à autoridade de Deus, dos velhos mestres ou 
do soberano. Em consequência, a faculdade inferior teria todo o direito de ser parte da universidade em um registro claro de autonomia, tanto em relação às faculdades superiores quanto perante os poderes externos. Antecipando a importância do primado da razão sobre todas as esferas de conhecimento humano, o texto kantiano propóe que a instituição universitária deixe de obedecer a princípios religiosos e políticos e que enfim se constitua como espaço livre, onde não haja soberano ou pontífice para atestar verdades mesmo nas faculdades superiores. A questão da autonomia aparece na Universidade no seu primeiro momento de modernidade e não como quezília caprichosa contra os poderes instituídos, mas como grito de liberdade do espírito humano, de confiança nas suas capacidades não tuteladas, em defesa do conhecimento científico, humano e portanto conjuntural, relativamente a outras formas de verdade reveladas ou impostas.

Para ter uma ideia sobre o ambiente intelectual que se vivia na Alemanha do início do século XIX em relação às políticas de ensino, cadinho no qual se havia de fortalecer a atmosfera de rejeição às premissas filosóficas da pedagogia utilitarista prevalecente e às instituições que encaravam o aluno como um corpo a ser domesticado na maquinaria do poder imperial que as controlava, vale a pena lembrar uma reflexão de Goethe, aliás membro activo do Conselho da Universidade de Iena: "Como quer alguém aparecer como mestre em sua matéria quando não ensina nada de inútil?”

No mesmo sentido crítico ao ambiente apertado da sala de aula, prelúdio de uma nova síntese que se adivinha entre a Universidade e o mundo externo, vai a resposta do estudante a Mefistófeles, na primeira parte do Fausto quando, referindo-se à Universidade, ele diz:

\footnotetext{
"Estas paredes, aulas, salas,

Não sei como hei-de suportá-las.

É tão restrito e angusto o espaço,

De verde não se vê pedaço,

E ficam-me nas aulas, bancos,

Pensar, ouvido e vista estancos."
}

Sabemos que o Rei, já não Frederico Guilherme II entretanto falecido, mas sim o seu filho e sucessor Frederico Guilherme III, entendeu e acolheu a crítica kantiana, cujas rigorosas bases de argumentação determinaram, a partir daí, um viés de extremo respeito das autoridades políticas perante o ponto de vista filosófico em relação ao ensino superior. Assim é que os Estados Germânicos, visando reestruturar-se após os conflitos napoleónicos, corrigindo as fragilidades estruturais que as primeiras derrotas, sobretudo a de Iena, tinham posto a nu, reformando o seu sistema de ensino superior e integrando-o no processo de desenvolvimento nacional, encomendaram projectos de universidade aos mais renomados filósofos da época. Ninguém menos que Fichte, Schelling e Schleiermacher apresentaram as suas contribuições; porém o vencedor desta espécie de "edital filosófico" da primeira grande reforma universitária foi Guilherme von Humboldt.

${ }^{1}$ GOETHE, J. W. von, Maximen und Reflexionen In: CONRADY, K.O., Goethe. Leben und Werk, Band. 2, Königstein: Athenäum, 1982/1984, \$445. 
Divulgado em 1810, o Relatório Humboldt estabelecia o primado da pesquisa, priorizando no ensino superior a outrora faculdade inferior, realizando assim a proposta kantiana. Baseava-se em uma premissa clara e muito simples: "a base da verdade para o ensino das faculdades inferiores deverá ser a pesquisa científica”. Do ponto de vista de organização do saber, a reforma humboldtiana consolidou o sistema de gestão académica com base no conceito da cátedra, instância de superposição orgânica entre o governo da instituição e a repartição dos campos de conhecimento. Neste conceito, estendido à noção de "liberdade de cátedra", para cada disciplina científica haveria um líder intelectual autónomo e responsável tanto pela gestão dos processos administrativos como pela gestão académica dos conteúdos curriculares.

Nesse referencial, a primeira universidade moderna a ser criada, foi a Universidade de Berlim, em 1810, totalmente organizada de acordo com os princípios e directrizes do Relatório Humboldt. Pela reforma humboldtiana, orientada por um forte espírito de liberdade individual de professores e de alunos, a pesquisa afirma-se como eixo de integração do ensino superior e fonte de credenciamento do que deve ser ensinado. A Universidade chama a si o mandato institucional e político sobre a responsabilidade da produção do conhecimento, que passa a constituir a sua segunda missão.

Embora com especificidades próprias, a maior parte das grandes Universidades de todo o mundo, ditas de investigação, vieram a ser fortemente influenciadas pelo modelo proposto por von Humboldt, facto que lhe garante um lugar de merecido destaque na História da Universidade.

Entretanto, podem ser identificados numerosos importantes momentos de criação e/ou desenvolvimento de estruturas universitárias dedicadas ao estudo das ciências e ao conhecimento científico da Natureza, anteriores à fundação da Universidade de Berlim, alguns deles verdadeiramente notáveis pela sua precocidade histórica ou pela sua dimensão.

Um dos primeiros destes episódios ocorreu ainda no século XVI, mais precisamente em 1587, quando a Universidade de Leiden se dotou de um Jardim Botânico (considerado um dos mais antigos da Europa) por iniciativa de Carolus Clusius, aliás Charles de l'Écluse, que aí plantou algumas espécies raras trazidas de Espanha e de Portugal, Países que visitara entre 1564 e 1565 e onde tivera acesso ao Colóquio dos Simples, de Garcia da Orta, que traduziu para latim e editou em 1567.

Em Portugal, é generalizada a ideia de que a reforma do sistema de ensino e a introdução do ensino da ciência acontecem com Pombal, muito embora uma interpretação menos superficial e menos esquemática da História nos obrigue a ser mais cautelosos. Parece, pelo menos, injusto, não referir que as iniciativas do Marquês se inserem num movimento cujo início as antecede, em pelo menos várias dezenas de anos.

Vai nesse sentido a afirmação categórica do Prof. Silva Dias em ensaio sobre a posição de Portugal na cultura europeia durante os séculos dezassete e dezoito, que transcrevo:

\footnotetext{
"Não há mais lugar para duas lendas importantes da nossa História: uma, a que figura a cultura escolástica parada nos conceitos do Curso Conimbricense, sem ulteriores progressos de carácter doutrinal ou mesmo científico; outra, a que pinta a renovação da cultura portuguesa como feito de Pombal, quando, na verdade, ela é independente do célebre ministro josefino e data, mesmo, de época anterior ao livro de Verney".
} 
Ao mesmo livro e com idêntico sentido se refere igualmente Fortunato de Almeida: (cito) "se não houvesse no tempo de D. João V um activo fermento científico e pedagógico, com orientaçôes e sistemas diversos, nunca Luís António Verney alcançaria o êxito que teve o seu Verdadeiro método de estudar, publicado em 1746, quatro anos antes da morte daquele monarca" e, dizemos nós, vinte e seis anos antes da Reforma Pombalina.

Ao livro de Verney é justo acrescentar ainda, como antecedentes históricos da reforma de Pombal, por exemplo, a obra e a influência de Cândido Lusitano, de António Félix Mendes e de Ribeiro Sanches.

Então como agora, as origens e os protagonismos das reformas eram multifacetados mas, aos olhos da História, estas quezílias são sempre resolvidas pelo cunho exclusivo do nome dos governantes. Não resisto a citar, a este propósito, Frei João Baptista em Os Frades julgados no Tribunal da razão, publicação póstuma de 1814:

"Os Regulares foram os primeiros que ensinaram publicamente em Coimbra a filosofia moderna. D. Carlos Maria Pimentel, nos Crúzios; os Doutores Frei Francisco de São Bento Barba e Frei Joaquim de Santa Clara, nos Beneditinos; e o Doutor Frei Alexandre da Silva, nos Gracianos. O mesmo método seguiram os professores que lhes sucederam, até à reforma da Universidade, que só teve lugar quinze anos depois que as escolas monásticas se tinham reformado a si mesmas".

É, portanto, da Reforma Pombalina que vamos agora falar, entendida como um profundo e coerente conjunto de iniciativas de governo, conduzidas por Pombal até ao mais ínfimo detalhe, iniciadas não muito depois do terramoto de 1755 e marcados pela criação da Aula do Comércio, em 1759, primeiro estabelecimento de ensino oficial do mundo a ensinar Contabilidade de uma forma técnico-profissional e do Real Colégio dos Nobres, em 1761, primeiro estabelecimento de ensino em Portugal a incluir no seu currículo o ensino experimental das ciências, cedo se reconhecendo, aliás, a inutilidade da tentativa face ao total desinteresse dos destinatários, que o consideravam inútil como preparação para a ociosa vida da aristocracia. Embora sejam os dois percursores de estabelecimentos de ensino universitário, no primeiro caso do actual Instituto Superior de Economia e Gestão da Universidade Técnica de Lisboa e no segundo da Escola Politécnica de Lisboa, transformada em 1911 na actual Faculdade de Ciências da Universidade de Lisboa, ambos são, no momento da sua formação, exteriores à Universidade. Depois, numa inversão de estratégia a que não terá sido alheia a extinção, entretanto ocorrida em 1759, da Companhia de Jesus no nosso País, com a total reestruturação do ensino médio que ela tornou inevitável e o encerramento definitivo da Universidade de Évora, a atenção do Marquês vira-se decididamente para a Universidade de Coimbra.

Pombal desejou, mais tarde, apresentar a sua reforma universitária como o resultado de uma longa preparação que remontaria ao início do reinado de D. José, em 1750. Segundo Eduarda Cruzeiro, os mais de seiscentos documentos relativos à Universidade abrangendo os anos 1750-72 parecem, no entanto, indicar sobretudo preocupações menores de despacho corrente, sendo que apenas em 1764 João Pereira Ramos de Azevedo é encarregado de reunir material para a reforma que há de fazer-se, e apenas em 1770, com a nomeação do Reitor Francisco de Lemos, homem da total confiança do Marquês e irmão mais novo de João Pereira Ramos, é que o processo entra numa fase decisiva. 
Eliminados os espíritos fortes que lhe dificultavam os movimentos no interior da Universidade, o Marquês via chegado o momento em que poderia concretizar a não disfarçada intenção de fazer dela um instrumento do seu poder de déspota esclarecido. Frustrados, por outro lado, os seus ensejos em fazer dos nobres criaturas minimamente cultas nas matérias científicas, com o insucesso da experiência no Real Colégio dos Nobres em Lisboa, a transferência para Coimbra dessas disciplinas representaria uma oportunidade para corrigir o tiro. Simultaneamente, juntava num único bloco o ensino das ciências e das humanidades, fazendo-as beneficiar mutuamente, como se diria hoje, das fecundas interacçôes epistemológicas que a proximidade propicia ou, com propósitos mais prosaicos, conseguia não dispersar os centros de conhecimento e de formação superior que era, como é sabido, a estratégia portuguesa neste domínio.

Seja o que for que tenha estado na base deste movimento, não é difícil aceitar, igualmente, que os desafios abertos pela exploração das colónias e nomeadamente a necessidade de uma administração forte e de um corpo técnico devidamente qualificado, tenham reforçado as habituais carências do País nessa matéria e contribuído para a decisão política de introduzir profundas reformas no ensino até então baseado, como se disse, na escolástica e nos livros.

O confronto dos portugueses com os imensos territórios que lhes era dado explorar, com uma fauna e flora exuberantes e em boa parte desconhecidas e com fenómenos novos que tiveram que dominar, tornou-os conscientes da imperiosa necessidade de aceder ao conhecimento das leis da Natureza e de, para tal, recorrer à chamada abordagem experimental. A erudição retórica pode ser capaz de inflamar as almas, mas dificilmente servirá para cuidar dos corpos, para compreender as coisas, para desbravar os continentes.

É, portanto, sintomática, a coincidência histórica entre um dos períodos de mais intensa exploração geográfica e colonial desses territórios, sob a égide de Pombal, e a profunda alteração ao sistema de ensino superior operada em Portugal, com as profundas alterações de organização e de métodos de ensino introduzidas na Universidade de Coimbra. Este movimento, que incluiu a criação do Gabinete de Física, do Laboratório Chimico, do Jardim Botânico, do Observatório Astronómico, do Dispensário Pharmacêutico, do Teatro Anatómico e do Museu de História Natural, ficou genericamente conhecido como a Reforma Pombalina da Universidade e constituiu, a par da laicização do ensino universitário e em complemento com ela, um momento de viragem com consequências importantes em todo o espaço de língua portuguesa. De uma visão misteriosa, metafísica, povoada de misticismo, de anjos que dividem a matéria, de matéria que tem horror ao vazio, em parte cristalizada nas várias criações do mundo inscritas nos textos religiosos, vemos desenvolver-se, contrapondo-se-lhe, uma atitude racionalista, experimental e quantitativa que vai revolucionar a nossa visão da natureza, ao longo do século XVIII até aos nossos dias, corrente na qual a Universidade portuguesa se incorpora a partir do terceiro quartel desse mesmo século.

E é nesta Universidade que vêm obter formação, desde o início da colonização mas sobretudo a partir do terceiro quartel do século XVIII, sucessivas gerações de jovens nascidos nas colónias proporcionando a consolidação de uma elite de intelectuais, cientistas e técnicos que desempenhou um papel importante no conhecimento, na formação e no desenvolvimento das novas nações. 
Sistematizando, temos a partir do século XVI, vários sucessivos momentos ao longo da História da Universidade em que esta vai incorporando as ciências da Natureza e dando cada vez mais espaço às abordagens experimentais. A metodologia científica vai conquistando o seu lugar, primeiro timidamente no interior das Faculdades ditas inferiores e depois, abrindo o caminho da racionalidade por entre as tensóes, as contradições e as restrições impostas à razão, por um tipo de verdade tutelada pelo poder temporal ou revelada pelos textos sagrados. Finalmente, na viragem do século XVIII para o XIX, a investigação científica emerge, em todo o seu esplendor e potencialidade, a partir do momento em que se reconhece à Universidade a capacidade de seguir o seu próprio caminho e de determinar as suas próprias orientações em matéria científica e pedagógica.

Qual é a importância de Coimbra e de Berlim neste processo? Coimbra ou Berlim? Marquês ou barão? De Pombal ou von Humboldt? São as perguntas que marcam a fronteira entre a última grande reforma da Universidade velha e a primeira grande reforma da Universidade nova.

Pombal já tinha percebido a importância das ciências experimentais e do primado da razão auditável sobre a razão tutelada. Mas, entre o seu despotismo esclarecido de meados do século XVIII e o despotismo esclarecido de Francisco Guilherme III do início do século XIX havia um mar de semelhanças e um oceano de diferenças: havia a distância colossal que separa o Antigo Regime, do Novo Regime. Havia a Revolução Francesa que a aristocracia Prussiana tinha finalmente derrotado, em combate de morte, no plano militar, mas com a qual tinha perdido, inexoravelmente, no plano das ideias.

Para mais, em lugar de uma obra basilar como $O$ Conflito das Faculdades, de que dispunha Berlim a partir de 1798, Coimbra só podia oferecer-se, como reflexão sobre a Universidade, o Compêndio Histórico do Estado da Universidade de Coimbra, diligentemente elaborado pela Junta de Providência Literária para fazer o levantamento das causas da degradação dos estudos superiores no Reino, que mais não é do que um repositório das posições do Marquês: uma impiedosa crítica à acção dos Jesuítas, considerados únicos responsáveis pela decadência e pela ruína da instituição, que só uma «nova fundação» poderia resgatar.

Enquanto que no texto de Kant se podem ler páginas luminosas de defesa e de incitação à liberdade de pensamento, a inspiração do Marquês radica sobretudo na preocupação de controlar os espíritos:

Veja-se, por exemplo, esta frase do início da Secção III do Conflito:

"Importa absolutamente que, na universidade, se dê ainda à comunidade erudita uma Faculdade que, independente das ordens do governo quanto às suas doutrinas, tenha a liberdade, não de proferir ordens, mas pelo menos de julgar todas as que têm a ver com o interesse científico, i.e., com o da verdade, em que a razão deve estar autorizada a publicamente falar; porque, sem semelhante liberdade, a verdade não viria à luz (para dano do próprio governo), mas a razão é livre por sua natureza e não acolhe nenhuma ordem para aceitar algo como verdadeiro (nenhum crede, mas apenas um credo livre). - Reside, porém, na natureza do homem a causa por que semelhante Faculdade, não obstante esta grande vantagem (da liberdade), é denominada inferior; com efeito, quem pode mandar, embora seja um humilde servo de outrem, imagina-se superior a outro que é, sem dúvida, livre, mas a ninguém tem de dar ordens". 
E compare-se com este outro preceito simples, a décima nona instrução dada por ordem do Marquês aos professores de Gramática Latina:

\begin{abstract}
"Terão os Professores também o cuidado de inspirar aos discípulos hum grande respeito aos legítimos superiores, tanto Eclesiásticos como seculares: Dando-lhes suavemente a beber, desde que nelles principiar a raiar a luz da razão, as saudáveis Maximas do Direito Divino e do Direito Natural, que estabelecem a união Christã e a Sociedade Civil: e as indispensáveis obrigações do Homem Christão, e do Vassallo, e Cidadão. Para cumprir com ellas na presença de Deos, e do seu Rei, e em benefício comum da sua Patria: Aproveitando-se para este fim dos exemplos, que forem encontrando nos livros do seu uso, para que desde a idade mais tenra vão tendo hum conhecimento das suas verdadeiras obrigações."
\end{abstract}

Entre os dois textos vai a distância de um abismo.

Enquanto procedia à reforma iluminista da sua Universidade, o Marquês mandava destruir e proibia livros de Diderot, Rousseau, Voltaire, La Fontaine, de conteúdo considerado ofensivo da paz e do sossego público e genericamente tidos como corruptores da Religião e da Moral. Era capaz de impor orientaçóes curriculares baseadas no método experimental e na Filosofia Racionalista, mas ao mesmo tempo mandava dotar as salas de aula de uma varanda, à qual só se acedia pelo gabinete do Reitor, e da qual se podia aferir o respeito dos Metres pelo Monarca e pelos texto sagrados.

Apanhada na encruzilhada entre o ideário do Pensamento Científico Iluminista e as Tradições Pedagógicas Escolásticas, e sem reflexão filosófica para resolver o conflito, a Reforma Pombalina adoptou uma estratégia de conciliação fundada sobre um certo eclectismo. Ao contrário, Humboldt é capaz de rasgar com o passado.

Coimbra, no terceiro quartel do século XVIII, tinha quase tudo para dar certo (tinha o Jardim Botânico, o Observatório Astronómico, o Dispensário Farmacêutico, o Teatro Anatómico, o Museu de História Natural, o Laboratório Químico, a Faculdade de Matemática, a Faculdade de Filosofia Natural, etc.), mas faltava-lhe o essencial: não tinha Goethe reclamando contra a opressiva realidade de uma Universidade virada para dentro, não tinha Kant reflectindo sobre as causas profundas da degradação e progressiva inutilidade da Universidade velha, faltou-lhe Humboldt, o genial sistematizador do pensamento e gestor da reforma. Aos cientistas e aos engenheiros, grupo ao qual ainda considero pertencer, isto dá que pensar: nunca conseguimos resolver as nossas equações sem o auxílio de quem não sabe resolver equações. Mais uma previsão de futuro de que a História é pródiga. E neste caso, só foi possível chegar à fórmula resolvente depois de inventar o conceito ao qual ainda hoje se chama autonomia universitária.

O conceito de autonomia universitária, postulado por Kant e densificado por Humboldt, na leitura actualizada que o passar dos anos torna obrigatória, continua a ser da maior centralidade para a compreensão da relação dialéctica entre a Universidade e o poder, e para a interpretação que a Universidade deve (ou pode) fazer da sua própria missão.

Pelas discussões que ainda hoje suscita, podemos perceber que a Autonomia não é um estatuto para sempre adquirido pelas universidades, antes deve ser permanentemente escrutinado pela comunidade, a cujas regras elas se devem considerar vinculadas e a cujos desígnios devem, em última análise, responder. 
Não sendo um direito definitivamente adquirido, a Autonomia Universitária também não é um capricho. O conceito é definido na Magna Carta das Universidades, que um número crescente de Universidades e de Governos vem subscrevendo, e é praticado em todos os países desenvolvidos por se entender que é indispensável ao bom funcionamento das Universidades e ao integral cumprimento das suas missões.

Ela começa por ser de natureza científica e pedagógica, nos tempos da afirmação da segunda missão e vai sendo progressivamente alargada a outras áreas tais como a administrativa e financeira, a estatutária e a disciplinar. Este processo é um "pau de dois bicos": se, por um lado, tende a conferir à Universidade a liberdade de espírito indispensável à procura da verdade científica e a liberdade de acção de que necessita para responder aos desafios com os quais se confronta, por outro lado favorece o distanciamento relativamente ao poder político, alimentado de ambas as partes por sentimentos pequenos de soberba e de orgulho ferido, por recriminações mútuas que vão criando condições para a divergência de percursos e para o alheamento. Só assim se explica o papel relativamente secundário atribuído pela Europa dos finais do século XX às suas Universidades, quando se tratou de tomar as mais importantes decisões políticas sobre a construção de Espaços integrados de ensino superior, de investigação e de conhecimento.

Frequentemente os universitários se envolveram em disputas estéreis e impuseram dicotomias conceptuais tão ao seu gosto, tantas vezes resolvidas, no curto prazo, a favor da Universidade (abusando do conceito de Autonomia), mas quase sempre perdidas por ela, a longo prazo, no plano da consideração pública e da cumplicidade social. Tantas vezes eles foram incapazes de fazer sínteses, como se lhes exigiria, ou de lançar pontes para o exterior, refugiando-se por detrás do poder balofo de quem fala de cátedra, interpretando a Autonomia da pior forma possível, impondo-a como barricada, ou fosso, por detrás do qual se organizam (ou se escondem!) "inexpugnáveis aldeias gaulesas, dotadas de um poder sobre-humano" porque detentoras de uma "poção mágica", que as torna capazes de "resistir, hoje e sempre, ao invasor". Retiro, como perceberam, estas duas últimas linhas da primeira página de qualquer uma das aventuras do Astérix.

Do outro lado estão comportamentos igualmente passíveis de caricatura. Para os Governos, a Autonomia representou, com demasiada frequência e facilidade, uma boa desculpa para a desresponsabilização sobre o sector, quando não argumentação para a peregrina ideia da desnecessidade de política pública, e um excelente resguardo numa área política sensível. Sobretudo num quadro de predominância liberal, quando uma decisão mais impopular é requerida em sede de definição de regras ou de regulação ou planificação do sistema, a questão é atirada com demasiada facilidade para a esfera da autonomia das instituiçôes e a decisão deixada ao livre arbítrio de cada uma delas. Uma profusão de exemplos ocorre à memória de todas quantos tenham ocupado cargos universitários nos últimos trinta e cinco anos.

Ora, a actividade das Universidades não pode deixar de ser exercida num quadro legal bem definido, que trace objectivos e imponha regras, sendo que a eficiência global do sistema depende, em larga medida, da clarificação destas regras e da adequada distribuição das responsabilidades entre os vários intervenientes. De facto, a ausência de regras sempre favorece a concorrência desqualificada, o que conduz ao nivelamento por baixo e portanto, à diminuição da qualidade. Por outro lado, não é 
razoável esperar-se que os problemas se resolvam através de mecanismos de auto-regulação, como a actual crise mundial do sistema financeiro, deixado demasiado tempo entregue a si mesmo e às chamadas regras de mercado, aí está para demonstrar.

A assunção do compromisso social da Universidade que está na base da definição da sua terceira missão, foi igualmente, a partir de meados do século XX, a oportunidade para equacionar os termos em que este dilema se coloca e para reinterpretar o conceito de Autonomia. Finalmente, quando as regras da sociedade moderna transportam para um novo patamar de exigência a gestão eficiente da coisa pública no mundo globalizado, parece ganhar uma nova premência a necessidade de trazer ao mesmo tabuleiro governos e Universidades e de os obrigar a adoptar comportamentos pragmáticos.

Sobretudo num momento em que todas as discussóes se centram em torno das questôes financeiras e todas as dúvidas se esclarecem em função de critérios exclusivamente financeiros, a definição equilibrada do conceito de Autonomia universitária, fundamentada na defesa do interesse público, deve saber situar-se acima dessa discussão e é um critério claro de modernidade na organização da sociedade, agora como desde há cerca de duzentos anos.

Várias abordagens têm sido prosseguidas, com resultados visivelmente diferentes. Estados Unidos e Japão, por exemplo, admitem a intervenção directa do mercado no Ensino Superior, mesmo através de entidades com fins lucrativos, mas perante um quadro regulatório bastante mais completo e eficaz que o nosso. Reino Unido e Nova Zelândia desenvolveram agências não-governamentais de interface, que regulamentam, avaliam e financiam o sector.

Procurando a síntese, a Autonomia Universitária não pode ser sinónimo de concorrência desqualificada ou de falta de exigência e de qualidade. O exercício da Autonomia pelas Universidades deve enquadrar-se no âmbito de um sistema regulado, e fundar no princípio da responsabilidade social das Universidades, que inclui o dever de prestar contas à sociedade dos recursos que esta lhes proporciona. Para isso, a Universidade tem o dever de instituir mecanismos adequados e idóneos de auto-avaliação, de se submeter a exercícios de avaliação externa e de dar publicidade aos resultados dessas avaliaçōes, quer perante a comunidade universitária, quer perante a opinião pública em geral. Em resposta, a Universidade tem o direito de ser envolvida na definição das políticas públicas e de exigir dos poderes públicos a atenção, a consideração e o apoio que o seu relevante papel social justifica.

Duzentos anos depois de ter sido conceptualizada, existe hoje tantas interpretaçôes do conceito de autonomia quantos os sistemas universitários que a pretendem respeitar, ou não. No texto de Kant, por exemplo, todo ele dedicado à defesa da autonomia universitária, a palavra autonomia é utilizada numa relação a tal ponto íntima com a palavra razão, que a primeira é considerada condição necessária para a segunda. Na única vez que aparece em todo o livro, claramente com o significado de autonomia intelectual ou científica pode ler-se:

“ao poder de julgar com autonomia, i.e., livremente, dá-se o nome de razão".

Um ex-ministro britânico colocou recentemente a questão da autonomia universitária em termos bem diferentes: Reportando-se, ele, à autonomia financeira disse: "As Universidades podem ter níveis medievais de autonomia se estiverem preparadas 
para aceitar níveis medievais de financiamento". De facto, vendo o problema na mera perspectiva do equilíbrio das contas, o financiamento público das Universidades e a autonomia financeira de que dispõem são recursos complementares. Com maior autonomia financeira elas serão capazes de gerar autonomamente mais recursos próprios que compensem a eventual diminuição das dotações públicas. Mas quando se mistura desse jeito autonomia e financiamento, sempre no calor de uma discussão apressada pela urgência de se fechar um orçamento, o saldo final nunca é favorável à Universidade. E retirar à Universidade financiamento público sem lhe dar meios, sob a forma do reforço da autonomia financeira, para ela aumentar as suas receitas próprias é atentar severamente contra a sua autonomia científica.

Portanto, o que a frase do ministro amargamente significa (como outras frases de outros ministros), à luz da definição de Kant que a antecedeu em duzentos anos é exactamente o seguinte:

As sociedades que só puderem proporcionar às suas Universidades níveis medievais de financiamento devem estar preparadas para receber delas níveis medievais de razão. Diminuição simultânea de financiamento e de autonomia financeira das Universidades é o caminho certo para o resultado errado: a diminuição do nível de razão, ou seja, do nível de desempenho universitário.

Os tempos que vivemos actualmente, sobretudo na Europa, não nos dão facilidades. Num Congresso sobre História da Ciência, o estudo das razões do surgimento e do papel desempenhado pela autonomia universitária pode ser de alguma utilidade para as decisôes do presente. 